\title{
Factors Determining Probability of Exceedance of Area Damaged by Fire
}

\author{
YUTAKA KOBAYASHI \\ Technology Center, Taisei Corporation \\ 344-1, Nase-Cho, Totsuka-ku, Yokohama, Japan
}

\begin{abstract}
A purely empirical procedure was presented at the Beijing symposium in 2005 to formulate fire losses based on fire statistics in Japan. The procedure is based on a non-liner soil mechanics formulation called Hardin-Drnevich model, fitting fairly well with the probability of exceedance of monetary loss and floor area damaged by fire observed in a number of types of fire-resistant building. The present paper is intended to summarize recent findings, focusing on factors determining the nonlinear characteristics of the empirical formulation in terms of area damaged by fire within the building of fire origin. First, the applicability of the model is examined for various building types remaining to be addressed. Then, some potential factors are analyzed for their effects on the occurrence of relatively small and more frequent damage. Finally, a more mechanistic model is proposed based on the analysis of timber house fires, relating the risk profile in the vicinity of the extreme with the dimension of properties at risk.
\end{abstract}

KEYWORDS: risk assessment, statistics, area damaged by fire, type of construction

NOMENCLATURE LISTING.

$P O E \quad$ probability of exceedance of a fire damage measure (fraction)

$P O E(1), P O E(10)$, etc. probability for a damage measure to exceed the unity, ten, etc. (fraction)

\section{INTRODUCTION}

\section{Background}

Fire statistics have been a crucial source of information on fire safety where such statistics are available ever since the pioneering work by Ramachandran [1]. In most cases, focus has been placed on extreme value distributions of monetary losses or the likelihood of monetary loss for a society / an economy at large to exceed a certain level under certain circumstances. To name a few recent examples, Hasofer et al. [2] discussed the US fire loss statistics focusing on year-by-year 99\% quantile from 1983 through 1995. Hanayasu et al. [3] dealt with industrial fires in Japan from the year 1989 to 1993. From these works, Tillander [4] differs in the sense that some attention was paid to not only monetary loss but also floor area damaged by fire regarding Finnish fires for the year 1996 to 1999; three types of construction (concrete, timber, and others) were compared in terms of cumulative frequency of both the damage measures. However, they were compared simply as such and no efforts appeared to formulate the cumulative frequency curves.

\section{The Author's Approach}

In contrast to the studies cited briefly above, the uniqueness of the author's empirical approach [5] can be summarized as follows:

- A non-linear material function called Hardin-Drnevich (HD) model [6] in soil mechanics is used to formulate the loss measure vs. probability of exceedance (POE) relationship (Fig.1).

- The model can represent the overall tendency of the fire risk from the minimum to the extreme, as far as some fire-resistant business-oriented buildings are concerned. Both monetary loss and floor area damaged can be dealt with using the same procedure.

- It is intended mainly to evaluate the fire risk of a specific property, not the society at large. To do this, it is necessary to gather as many relevant statistical records [7] as possible in buildings specifically similar to the objective property, in such terms as usage, structural type, floor area, number of floors, availability of automatic extinguishing system, etc. 
It should be repeated that only a limited number of building categories have been tested for their wellness of fit to the HD model:

- The author's discussion has been limited to such property uses as office, retail store, hotel, school, factory, etc. Thus, residential buildings and warehouses have not been given attention to.

- Type of construction: The focus has been on fire-resistant buildings. Other types of construction have remained to be investigated.

Furthermore, since the model was obtained purely empirically, there has been no explanation why the risk curves look as such and can be well represented by such an essentially bi-linear function as HD model. The current paper is intended to step forward for answers to these issues.

\section{Brief Description of The HD Model}

HD model $[5,6]$ is intended to represent the shape of fire risk curves defined in between a fire damage measure and the probability of a fire to exceed a certain level of the fire damage (Probability of Exceedance, POE). Equations (1) and (2) can represent the relationship between a damage measure, Y, and POE, denoted X, both plotted on a logarithmic scale, as schematized in Fig. 1. The nonlinear term in Eq. (1) borrowed from Hardin-Drnevich [6] primarily determines the profile in the range of smaller fire damage: the nonlinear term starts with $\mathrm{G}_{1}$ in terms of the slope (or "stiffness" in the analogy of material mechanics), reaching half of the maximum value $\mathrm{T}$ at "strain" $\mathrm{S}$, ultimately approaching its maximum value of $\mathrm{T}$. By adding a linear term including $G_{2}$ if necessary, it is possible for the overall function to have an arbitrary stiffness near the extreme damage. The parameters in these equations can be determined by following the steps shown in Table 1. See [5] for details of the procedure.

Table 1. Steps to Be Taken for Estimating Model Parameters

\begin{tabular}{|c|l|}
\hline Steps & \multicolumn{1}{|c|}{ Task to Do } \\
\hline Step 1 & Pick up statistic data of interest and count the number of data $\left(\mathrm{N}_{\mathrm{ALL}}\right)$. \\
\hline Step 2 & Sort the data in descending order of the damage measure of interest $(\mathrm{X})$. \\
\hline Step 3 & Delete zero-damage data and count non-zero data $\left(\mathrm{N}_{\mathrm{NON}-\mathrm{ZERO}}\right)$. POE $(1)=\mathrm{N}_{\mathrm{NON}-\mathrm{ZERO}} / \mathrm{N}_{\mathrm{ALL}}$. \\
\hline Step 4 & Determine HD model parameters using eqs. (1) and (2), where $\mathrm{Y}$ is POE per non-zero damage event. \\
\hline Step 5 & Define POE per all event as POE $(1)^{*} \mathrm{Y}$. \\
\hline
\end{tabular}

$\log (X)=G_{1} \times \frac{\log (Y)}{1+\log (Y) / S}+G_{2} \times \log (Y)$

$S=T / G_{1}$

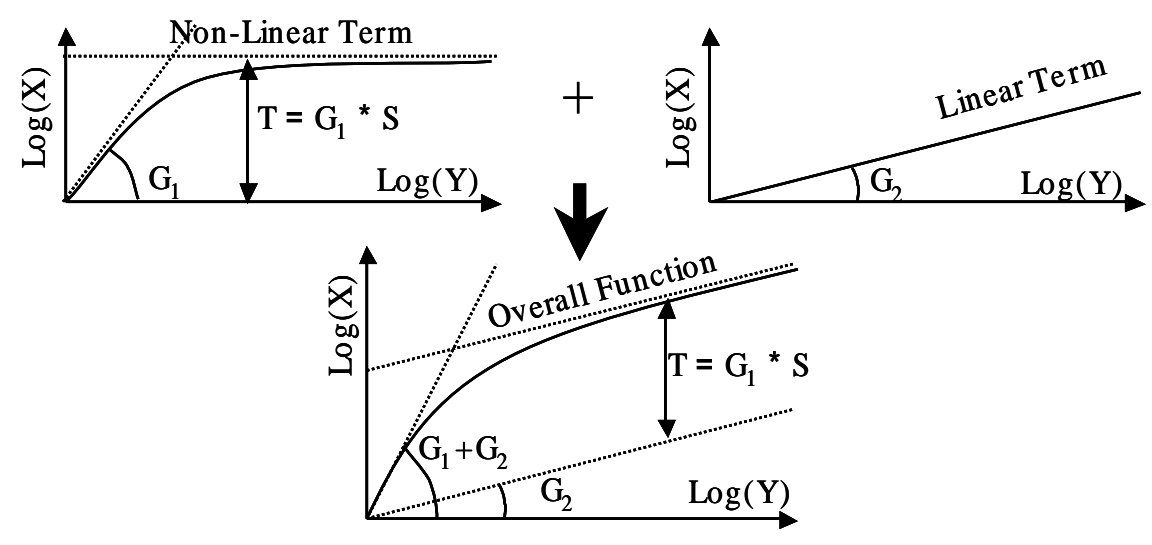

Fig. 1. Schematic Representation of Hardin-Drnevich Model. 


\section{On the Notion of "Probability of Exceedance" Herein}

The notion of "probability of exceedance" in the context of risk assessment generally refers to the probability of an event to incur a damage exceeding a certain level of damage measure within a given period (a year, most typically.)

Note, however, that the probability of exceedance designated as "POE" throughout the current paper lacks the notion of time. The term "probability of exceedance," or $\operatorname{POE}(\mathrm{X})$ herein denotes, within a group of relevant fire records, the ratio of the number of fires whose damage exceeds a level of " $X$ " either to the number of all non-zero damage fires (POE per non-zero damage event) or to that of all fires (POE per all events.) In all the risk curves below, "POE" denotes the latter: the ratio of " $\mathrm{X}$ " or more damage incurring fires to all the relevant fires given in fraction terms (not in percentage terms). To include the notion of time, the probability of a fire to take place within the building of interest needs to be taken into account. A procedure to do so while taking account of the size of the building is given in [5].

\section{APPLICABILITY OF THE HD MODEL}

\section{Fitting Data from Buildings in General}

As stated above, only a limited number of building types were investigated in the previous paper [5]. Therefore, the section is intended to test the model's validity for a wider range of building characteristics. Table 2 summarizes the number of statistical data used here as well as the model parameters identified by the procedure, while Fig. 2 compares observed (circles) and model (solid line) risk curves. There are six uses of building representing a range of fixed property use: office, retail store, factory, warehouse, detached house and apartment, in three types of building construction: fire-resistant (FR), quasi-fire-resistant (QFR), and timber buildings. The statistics are from 1995-2001.

A few remarks would be in order on fire-resistant (FR) and quasi-fire-resistant (QFR) buildings in Japan. The former include reinforced concrete buildings whose structural members satisfy the requirements on minimal cross-sectional dimensions. Also included are steel buildings with appropriate fire protection on columns and beams whose fire ratings range from one to three hours depending on the number of stories of the building.

Quasi-fire-resistant buildings include a variety of construction types, all of which are regarded as next to FR buildings in Japan. Note the data designated as QR herein only cover fires from non-timber buildings using masonry, concrete block, steel and other building components, whose fire ratings are equal to or less than 45 minutes.

The measure of fire damage here is area damaged by fire within the building of fire origin. Logically, therefore, the damage should not exceed the upper limit: the floor area of the building of fire origin, which is also documented event by event in the statistics.

When comparing the types of construction in Fig. 2, fire risks in the range of a relatively small damage become smaller in the order timber, quasi-fire resistant, and fire-resistant buildings. This appears natural since various building regulatory requirements become stricter in the order: size of compartment, flammability of interior materials, installation of automatic suppression system, etc.

However, it is not necessarily so in the vicinity of the extreme damage. For example, fire-resistant offices and warehouses given in Fig. 2 (a) and (d) show larger fire risks close to extreme damages than other construction types. This appears to suggest that not the strictness of regulations on the positive side, but the maximum size of the building at risk or the compartments within, presumably larger in fire-resistant than in timber buildings, plays an important (negative) role in determining the fire risks in the vicinity of the extreme.

Comparing the model and the statistics, HD model appears to fit fairly well in general with the statistical data and represent the tendency mentioned above. When closely looked at, however, the current model appears to have a difficulty in representing the statistics under some conditions, mostly near the extreme damage. A case in point here is fire-resistant residential apartments (Fig. 2 (f)). The model's deviation from the realities is evident beyond 100 square meters of damage or below 1/1000 per event in POE terms. 
Table 2. Building Categories Tested.

\begin{tabular}{|c|c|c|c|c|c|c|c|}
\hline Use of Building & $\begin{array}{c}\text { Type of } \\
\text { Construction }\end{array}$ & $\begin{array}{l}\text { Number of } \\
\text { Total Data }\end{array}$ & $\begin{array}{c}\text { Number of } \\
\text { Non-Zero } \\
\text { Damage Data }\end{array}$ & POE(1) & G1 & G2 & S \\
\hline \multirow{3}{*}{ Office } & FR & 649 & 135 & 0.208 & 3.897 & 0.686 & 0.446 \\
\hline & QFR & 403 & 228 & 0.566 & 11.064 & 0.260 & 0.210 \\
\hline & Timber & 368 & 235 & 0.639 & 14.436 & 0.287 & 0.152 \\
\hline \multirow{3}{*}{ Retail Shop } & FR & 877 & 89 & 0.101 & 5.095 & 0.000 & 0.792 \\
\hline & $\overline{Q F R}$ & 775 & 197 & 0.254 & 8.709 & 0.002 & 0.432 \\
\hline & Timber & 351 & 203 & 0.578 & 14.330 & 0.293 & 0.167 \\
\hline \multirow{3}{*}{ Factory } & FR & 545 & 125 & 0.229 & 13.824 & 0.788 & 0.166 \\
\hline & QFR & 3717 & 1086 & 0.292 & 15.684 & 0.492 & 0.176 \\
\hline & Timber & 804 & 438 & 0.545 & 27.714 & 0.339 & 0.102 \\
\hline \multirow{3}{*}{ Warehouse } & FR & 237 & 82 & 0.346 & 9.619 & 0.945 & 0.217 \\
\hline & QFR & 1358 & 743 & 0.547 & 20.191 & 0.781 & 0.102 \\
\hline & Timber & 1326 & 1039 & 0.784 & 21.666 & 0.481 & 0.094 \\
\hline \multirow{3}{*}{ Detached House } & FR & 1659 & \begin{tabular}{|l|}
878 \\
\end{tabular} & 0.529 & 10.326 & 0.000 & 0.247 \\
\hline & QFR & 2031 & 1136 & 0.559 & 10.543 & 0.076 & 0.231 \\
\hline & Timber & 61690 & 39150 & 0.635 & 15.540 & 0.000 & 0.175 \\
\hline \multirow{3}{*}{ Apartment } & FR & 18531 & 4798 & 0.259 & 6.503 & 0.000 & 0.383 \\
\hline & QFR & 1880 & 724 & 0.385 & 4.932 & 0.000 & 0.572 \\
\hline & Timber & 4331 & 2172 & 0.502 & 7.851 & 0.000 & 0.399 \\
\hline
\end{tabular}
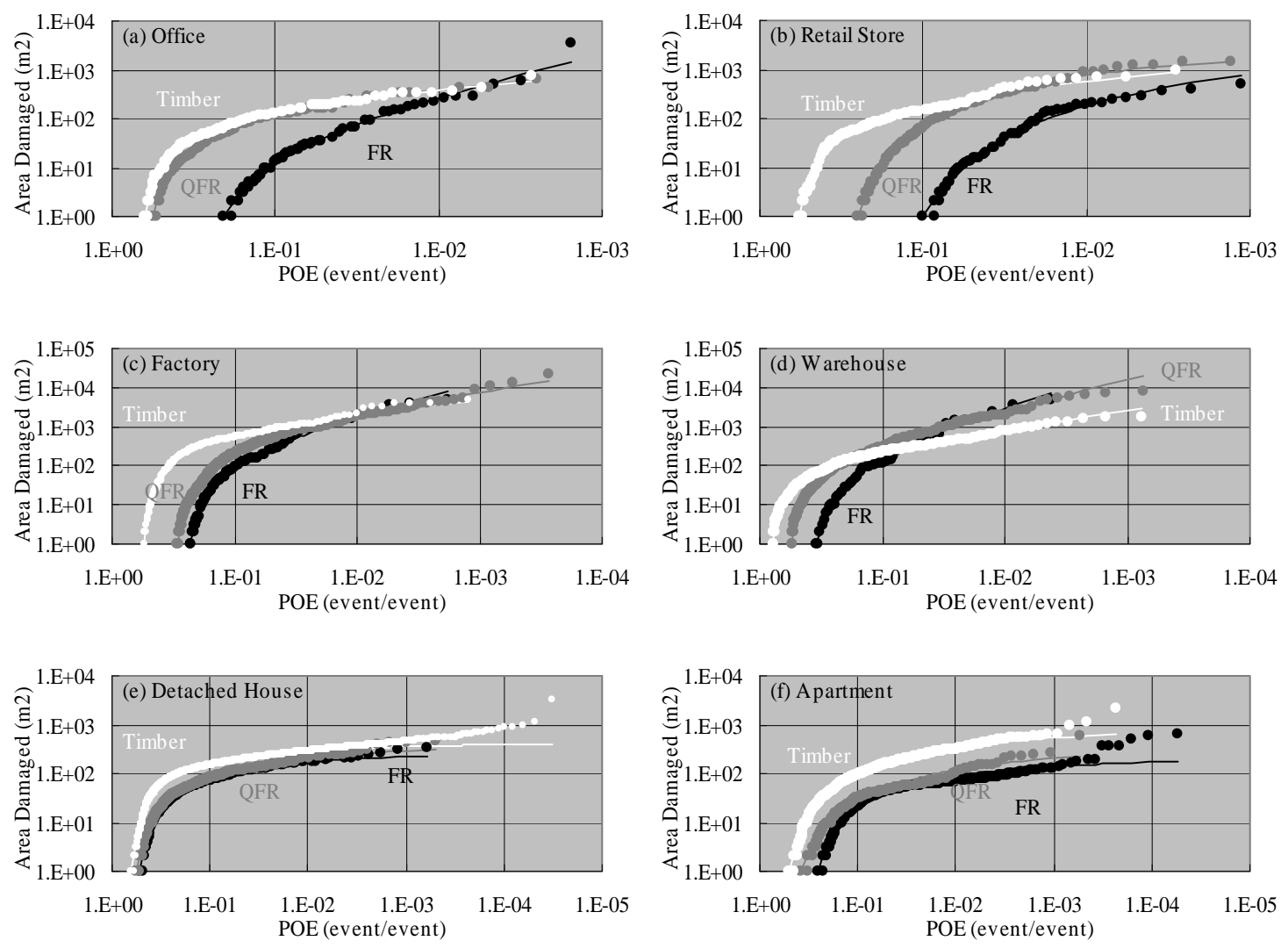

Fig. 2. Risk Curves for Various Usages

\section{Distinctions of Two Different Categories of Risks}

After some considerations, it was clarified that a group of data from Kobe during some days after the earthquake in 1995 caused the above-mentioned deviation of the model from the data. Table 3 shows worst 10 fire-resistant apartment fires in Japan in 1995-2001 in terms of area damaged by fire. Four out of top 
five fires (shaded lines) occurred on or just after the day of the earthquake on January 17, 1995 in Hyogo Prefecture, where Kobe is the largest city in population. By cross-checking the statistical information against earthquake damage reports found in literature [8], it was found that at least three of the four events corresponded to a substantial seismic damage prior to fire, resulting in local collapse of a story, ending up crushing and igniting an object. In these cases, fire spread at least two more stories above fire origin, damaging two or more compartments / apartment units. Though not related to an earthquake, the second largest damage of 580 square meters, recorded in an event in Hiroshima in October 1996, was also a multiple compartment / apartment fire in a 20-story building. The fire originated on the $9^{\text {th }}$ floor, spreading up by way of balconies, finally reaching the top of the building [9].

Table 3. Worst Ten Fire-Resistant Apartment Fires in Japan in 1995-2001.

\begin{tabular}{|r|r|r|l|r|r|r|}
\hline Year & Month & Day & Prefecture & $\begin{array}{c}\text { Number of } \\
\text { Stories Above } \\
\text { Ground }\end{array}$ & $\begin{array}{c}\text { Floor Area } \\
\text { (m2) }\end{array}$ & $\begin{array}{c}\text { Area } \\
\text { Damaged by } \\
\text { Fire (m2) }\end{array}$ \\
\hline 1995 & 1 & 17 & Hyogo & 6 & 3586 & 661 \\
\hline 1996 & 10 & 28 & Hiroshima & 20 & 66064 & 580 \\
\hline 1995 & 1 & 17 & Hyogo & 3 & 489 & 489 \\
\hline 1995 & 1 & 17 & Hyogo & 9 & 17019 & 371 \\
\hline 1995 & 1 & 17 & Hyogo & 5 & 2733 & 363 \\
\hline 1998 & 3 & 7 & Others & 7 & 6719 & 362 \\
\hline 1995 & 8 & 25 & Others & 6 & 2269 & 187 \\
\hline 1995 & 3 & 19 & Others & 4 & 665 & 187 \\
\hline 2000 & 7 & 20 & Others & 5 & 2899 & 183 \\
\hline 1996 & 1 & 30 & Others & 5 & 3260 & 175 \\
\hline
\end{tabular}

Focusing on Hyogo fire incidents, there exist 1295 apartment fires from FR buildings in 1995-2001. The data are divided into two components as below according to the date of fire:

- Post-Earthquake Fires: fires taking place in the prefecture on January 17-19, 1995.

- Non-Post Earthquake Fires: fires on other days in 1995 to 2001

Table 4 gives the amount of data as well as estimated HD parameters. Figure 3 compares three series of risk curves: post-earthquake, non-post earthquake, and overall data. It should be noted that the model curves are estimated (solid lines) from post-earthquake and non-post earthquake data respectively. The model for the overall data is a simple summation of the two components along area damaged by fire. By separating the post-earthquake fires from the bulk of the total fire data this way, it is possible for the model (and the summation of the models) to fit not only earthquake- and non-earthquake related fires respectively but also the overall risks up to the vicinity of the extreme value.

Table 4. FR Apartment Fires in Hyogo Prefecture: Data and Model Parameters.

\begin{tabular}{|l|l|r|r|r|r|c|}
\hline \multicolumn{1}{|c|}{ Category } & \multicolumn{1}{|c|}{ Period } & Data & POE(1) & \multicolumn{1}{c|}{ G1 } & \multicolumn{1}{c|}{ G2 } & S \\
\hline All Fires & $1995.1 .1-2001.12 .31$ & 1295 & 0.290 & NA & NA & NA \\
\hline Post-Earthquake & $1995.1 .17-1995.1 .19$ & 27 & 0.667 & 31.903 & 1.006 & 0.056 \\
\hline Non-Post Earthquake & $1995.1 .1-1995.1 .16$ and 1995.1.20-2001.12.31 & 1268 & 0.282 & 6.880 & 0.000 & 0.339 \\
\hline
\end{tabular}

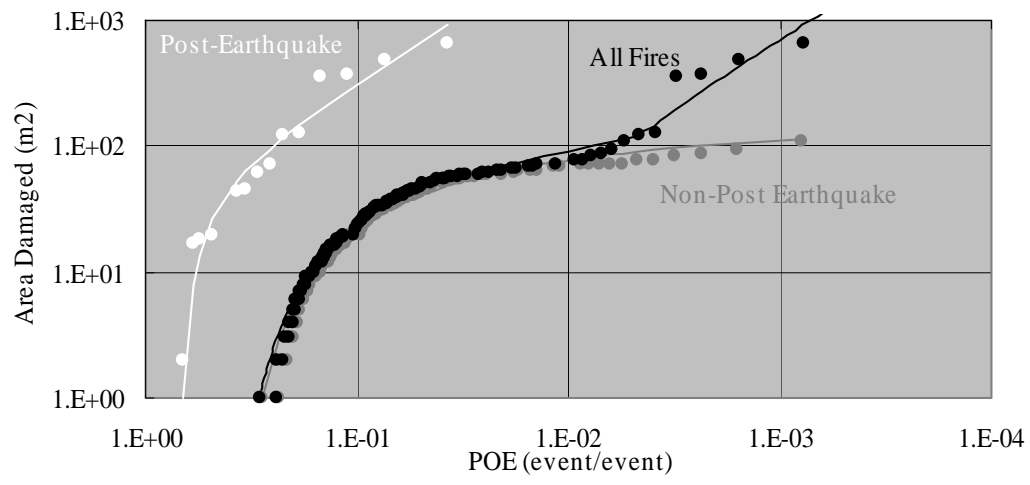

Fig. 3. Risk Curve Comparison Between Earthquake- and Non-Earthquake Fires. 


\section{Limitations of the Model}

There still remain some limitations of the model. Another case in point is detached houses made of timber. The richness of statistical data for the properties (of more than 60 thousand records in seven years, see Table 2) enable to draw and compare risk curves floor area by floor area. Figure 4 summarizes the amount of data against the floor area at risk. It should be pointed out that the above-mentioned richness of data provides well more than 500 fire events at the peak of floor area distribution shown in Fig. 4.

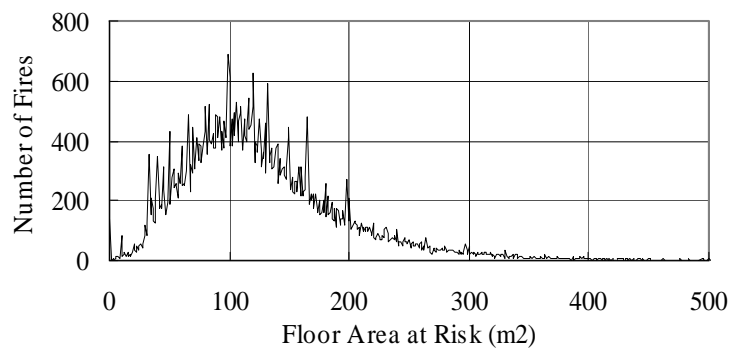

Fig. 4. Number of Data by Floor Area at Risk.

Figure 5 compares risk curves each representing the data from the detached houses whose total floor area vary from 20 to 300 at an interval of 20 square meters. Apparently, the risk curves shown in Fig. 5 flatten exactly at the floor area at risk for each data set since, by definition, the area damaged by fire here never exceeds the floor area of the building. In these cases, the current model will not be valid any more; a curve and a horizontal line will suffice to represent the tendency. The length of a horizontal line in Fig. 5 indicates the contribution of houses completely damaged by fire and the curvature below the plateau represents the tendency of the fire risks prior to complete damage. Based on these findings, the final section prior to conclusions below discusses a simple but a little more mechanism-oriented model than the current one.

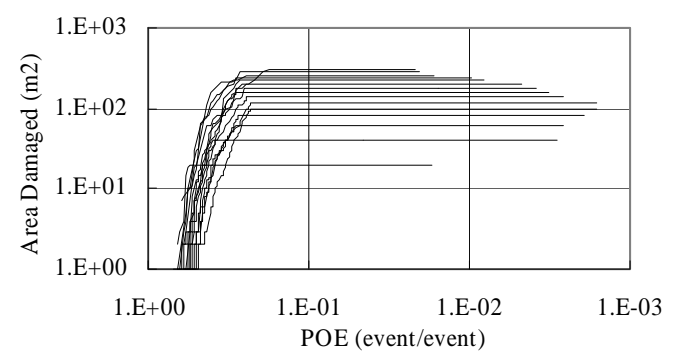

Fig. 5. Risk Curves for Timber Houses.

\section{FACTORS DETERMINING RELATIVELY SMALL LOSSES}

\section{Variance by Area of Fire Origin}

In the fire statistics of Japan, it is possible to distinguish the use of the room of fire origin in case of building fire. Statistical data are picked up and analyzed for fires originating in rooms for uses in Table 5 in the three types of construction. The analysis here focuses on events occurring with a relatively high frequency: the probability for area damaged by fire to exceed the unity (the minimum value identifiable in statistics) or a value of 10 , denoted here POE(1) and POE(10), respectively. POE(1) for various room uses are compared among construction types in Fig. 6 . It is evident that POE(1) varies substantially by room use, tending to be smaller in the order timber, quasi-fire resistant and fire-resistant buildings for reasons similar to those mentioned on Fig. 2. The same holds true for POE(10) as well though not shown here.

Two potential determining factors in these lower-end fire risks are investigated in the paragraphs below: success of early-stage suppression and fire loads contained in the room of fire origin. The former information is available in the statistics while the latter relies on sources other than fire statistics. 
The size of the room of origin, varying apparently by use of room, might play some role in determining the probability of even such small damages as 1-10 square meters. However, the current statistics in Japan lacks in the information. The question needs to be addressed in the future hopefully by using the alternative procedure described sections below in one way or another.

Table 5. Statistics by Room of Fire Origin.

\begin{tabular}{|c|c|c|c|c|c|c|c|c|c|c|c|c|c|c|c|c|}
\hline \multirow{2}{*}{ Use of Room } & \multicolumn{3}{|c|}{ Number of Data } & \multicolumn{3}{|c|}{ POE(1) } & \multicolumn{3}{|c|}{ POE(10) } & \multicolumn{3}{|c|}{$\begin{array}{l}\text { Extinguishment } \\
\text { Trial/Event Ratio }\end{array}$} & \multicolumn{3}{|c|}{$\begin{array}{c}\text { Extinguishment } \\
\text { Success/Event Ratio }\end{array}$} & \multirow{2}{*}{$\begin{array}{c}\text { Design } \\
\text { Fuel } \\
\text { Load } \\
\mathrm{MJ} / \mathrm{m} 2\end{array}$} \\
\hline & 寽 & 兟 & 音 & 寽 & 㒬 & 亗 & $\stackrel{x}{1}$ & 兟 & 言 & $\frac{x}{x}$ & 晃 & 高 & $\frac{x}{x}$ & $\frac{x}{d x}$ & 竎 & \\
\hline Living Room & 10053 & 2467 & 32048 & 0.51 & 0.68 & 0.77 & 0.37 & 0.53 & 0.67 & 0.64 & 0.65 & 0.63 & 0.38 & 0.31 & 0.24 & 720 \\
\hline "Oshiire" Closet & 333 & 103 & 1328 & 0.56 & 0.73 & 0.81 & 0.37 & 0.52 & 0.67 & 0.68 & 0.65 & 0.64 & 0.38 & 0.26 & 0.21 & 720 \\
\hline Dining & 1700 & 215 & 1116 & 0.19 & 0.39 & 0.49 & 0.10 & 0.27 & 0.34 & 0.80 & 0.76 & 0.81 & 0.66 & 0.51 & 0.50 & 720 \\
\hline \begin{tabular}{|l|} 
Entrance Lobby \\
\end{tabular} & 972 & 170 & 1211 & 0.16 & 0.32 & 0.51 & 0.08 & 0.21 & 0.39 & 0.58 & 0.58 & 0.70 & 0.49 & 0.40 & 0.38 & 160 \\
\hline Corridor & 2842 & 270 & 1513 & 0.09 & 0.27 & 0.63 & 0.04 & 0.17 & 0.49 & 0.66 & 0.74 & 0.70 & 0.58 & 0.59 & 0.36 & 32 \\
\hline Home Kitchen & 8398 & 1884 & 21255 & 0.20 & 0.36 & 0.49 & 0.08 & 0.17 & 0.32 & 0.83 & 0.83 & 0.82 & 0.68 & 0.60 & 0.51 & 720 \\
\hline Bathroom & 414 & 117 & 3528 & 0.28 & 0.44 & 0.60 & 0.08 & 0.25 & 0.40 & 0.66 & 0.68 & 0.78 & 0.50 & 0.43 & 0.34 & \\
\hline \begin{tabular}{|l} 
Toilet \\
\end{tabular} & 1593 & 297 & 629 & 0.09 & 0.20 & 0.52 & 0.03 & 0.06 & 0.27 & 0.67 & 0.71 & 0.69 & 0.59 & 0.58 & 0.34 & \\
\hline \begin{tabular}{|l|} 
Factory \\
\end{tabular} & 1416 & 6995 & 4591 & 0.23 & 0.32 & 0.68 & 0.19 & 0.27 & 0.61 & 0.73 & 0.73 & 0.66 & 0.42 & 0.36 & 0.24 & \\
\hline Restaurant Kitchen & 1814 & 764 & 1713 & 0.23 & 0.37 & 0.48 & 0.09 & 0.21 & 0.32 & 0.83 & 0.77 & 0.80 & 0.63 & 0.51 & 0.44 & \\
\hline Boiler & 125 & 126 & 987 & 0.18 & 0.40 & 0.64 & 0.07 & 0.23 & 0.41 & 0.70 & 0.74 & 0.82 & 0.42 & 0.29 & 0.33 & \\
\hline Garage & 635 & 749 & 1547 & 0.20 & 0.41 & 0.60 & 0.14 & 0.32 & 0.52 & 0.76 & 0.72 & 0.73 & 0.48 & 0.38 & 0.33 & 240 \\
\hline \begin{tabular}{|l} 
Indoor Parking Space \\
\end{tabular} & 1263 & 253 & 268 & 0.09 & 0.25 & 0.61 & 0.06 & 0.16 & 0.42 & 0.78 & 0.72 & 0.73 & 0.58 & 0.44 & 0.31 & 240 \\
\hline Storage & 1119 & 2833 & 10680 & 0.35 & 0.65 & 0.84 & 0.24 & 0.52 & 0.69 & 0.68 & 0.61 & 0.63 & 0.42 & 0.22 & 0.16 & 2000 \\
\hline Exterior Storage & 741 & 637 & 2122 & 0.17 & 0.52 & 0.77 & 0.08 & 0.39 & 0.56 & 0.77 & 0.67 & 0.70 & 0.55 & 0.25 & 0.20 & \\
\hline Retail Space & 986 & 537 & 638 & 0.17 & 0.33 & 0.60 & 0.11 & 0.26 & 0.49 & 0.72 & 0.65 & 0.64 & 0.57 & 0.48 & 0.29 & 480 \\
\hline Restaurant & 1283 & 420 & 1009 & 0.32 & 0.49 & 0.60 & 0.18 & 0.37 & 0.49 & 0.60 & 0.59 & 0.55 & 0.41 & 0.34 & 0.27 & 480 \\
\hline \begin{tabular}{|l} 
Office \\
\end{tabular} & 804 & 532 & 455 & 0.35 & 0.64 & 0.74 & 0.22 & 0.50 & 0.60 & 0.52 & 0.49 & 0.52 & 0.40 & 0.25 & 0.24 & 560 \\
\hline Rest Room & 400 & 276 & 431 & 0.34 & 0.68 & 0.69 & 0.21 & 0.51 & 0.57 & 0.64 & 0.55 & 0.51 & 0.48 & 0.29 & 0.21 & \\
\hline Unoccupied Room & 173 & 177 & 1508 & 0.61 & 0.64 & 0.78 & 0.48 & 0.55 & 0.69 & 0.25 & 0.36 & 0.46 & 0.14 & 0.14 & 0.15 & \\
\hline Under Construction & 326 & 156 & 299 & 0.29 & 0.39 & 0.57 & 0.20 & 0.34 & 0.40 & 0.75 & 0.79 & 0.58 & 0.51 & 0.36 & 0.29 & \\
\hline Balcony & 1484 & 149 & 589 & 0.08 & 0.19 & 0.35 & 0.03 & 0.05 & 0.15 & 0.84 & 0.86 & 0.87 & 0.70 & 0.66 & 0.56 & 80 \\
\hline Attic & 266 & 376 & 1602 & 0.13 & 0.19 & 0.57 & 0.08 & 0.14 & 0.46 & 0.61 & 0.72 & 0.70 & 0.36 & 0.40 & 0.23 & 80 \\
\hline Inside of Wall & 117 & 242 & 1767 & 0.15 & 0.29 & 0.48 & 0.09 & 0.22 & 0.34 & 0.70 & 0.76 & 0.77 & 0.36 & 0.33 & 0.28 & \\
\hline Exterior & 1212 & 1539 & 8981 & 0.10 & 0.31 & 0.49 & 0.05 & 0.24 & 0.37 & 0.68 & 0.69 & 0.77 & 0.48 & 0.35 & 0.37 & \\
\hline Others & 638 & 387 & 1820 & 0.13 & 0.37 & 0.58 & 0.06 & 0.25 & 0.42 & 0.71 & 0.65 & 0.65 & 0.53 & 0.36 & 0.30 & \\
\hline
\end{tabular}

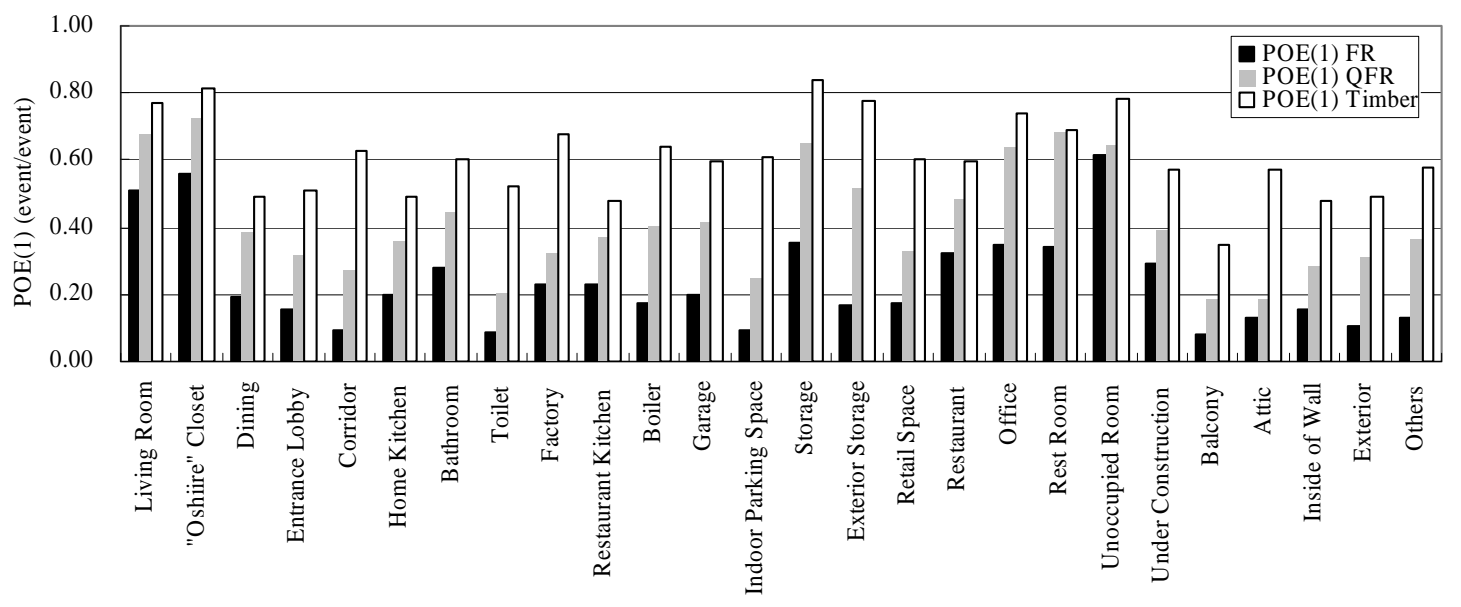

Fig. 6. POE(1) for Various Room Uses.

\section{Dependence on Early-Stage Extinguishing Efforts}

Early-stage fire extinguishing efforts are defined in the statistics by any actions taken to do so prior to arrival of fire department, whether by automatic extinguishing systems, by portable fire extinguishers, or by any other measures. Based on relevant entries in the statistics, it is possible to identify event by event, (a) 
whether or not such an effort was made at all in early stage, (b) if yes, what measure was taken, and (c) if, after all, the effort was successful, or more precisely, deemed successful by the investigator.

Figures 7 and 8 summarize the effect of such efforts on frequent fire damages, where each dot represents a use of room in a building of a construction type in Table 5. Extinguishment Trial/Event Ratio, defined here by the ratio of events with such efforts to overall fires, seems to have only a weak negative correlation with POE, while Success/Event Ratio is strongly related to both POE(1) and POE(10).

Though Trial/Event Ratio is confirmed to be relatively consistent among types of construction, Success/Event Ratio tends systematically to decrease in the order of FR, QFR, and timber buildings, causing the difference in correlations between Figs. 7 and 8. This is probably because the quality of extinguishment measures is higher in FR buildings than other buildings. Further analysis is due to look into the measures taken in early stage.
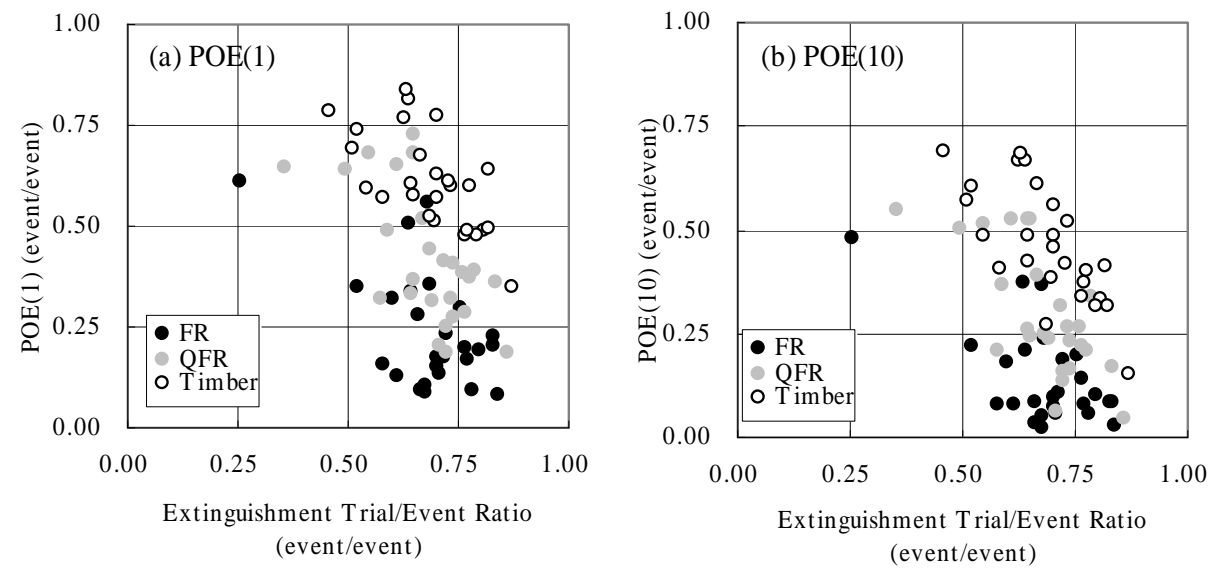

Fig. 7. POE vs. Early-Stage Extinguishment Trial/Event Ratio.
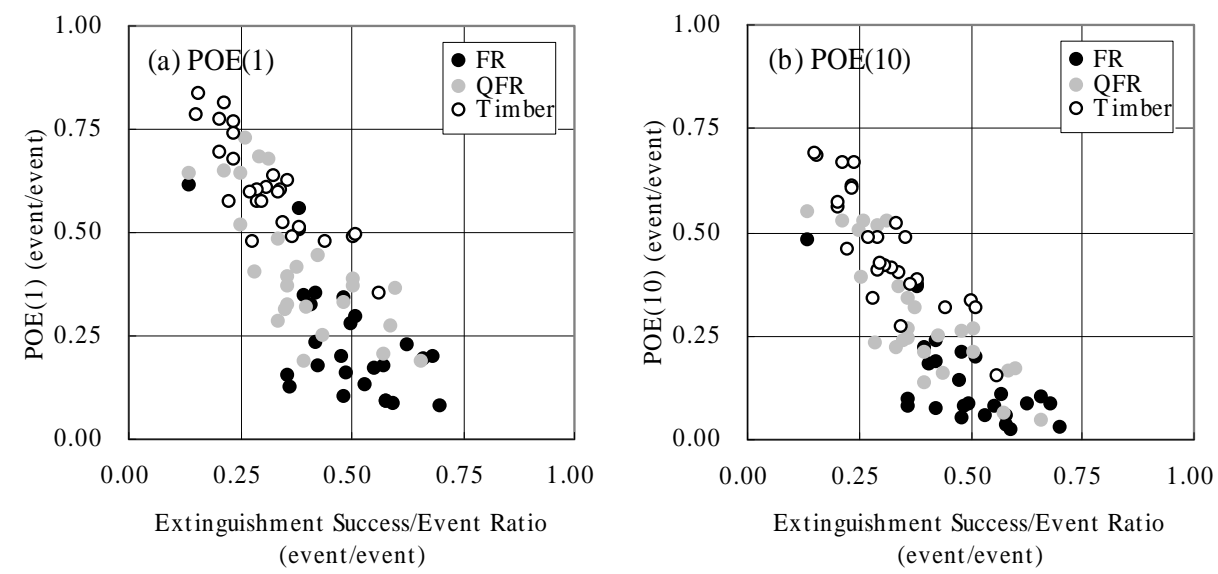

Fig. 8. POE vs. Early-Stage Extinguishment Success/Event Ratio.

\section{Dependence on Fuel Loads}

Another potential explanation for the variance of small damage probabilities is the amount of fuel loads, presumably varying as well by use of room. Under the current Building Standard Law, design-basis fuel loads are available for a limited number of uses of room [10]. The rightmost column in Table 5 shows the values if deemed apparently applicable. Figure 9 shows POE(1) and POE(10) plotted against fuel loads on a logarithmic scale. Though the correlation varies substantially with different construction types and the 
timber building data show the weakest relation, it would be possible to assume that fuel loads may have a positive correlation with these frequent damages.
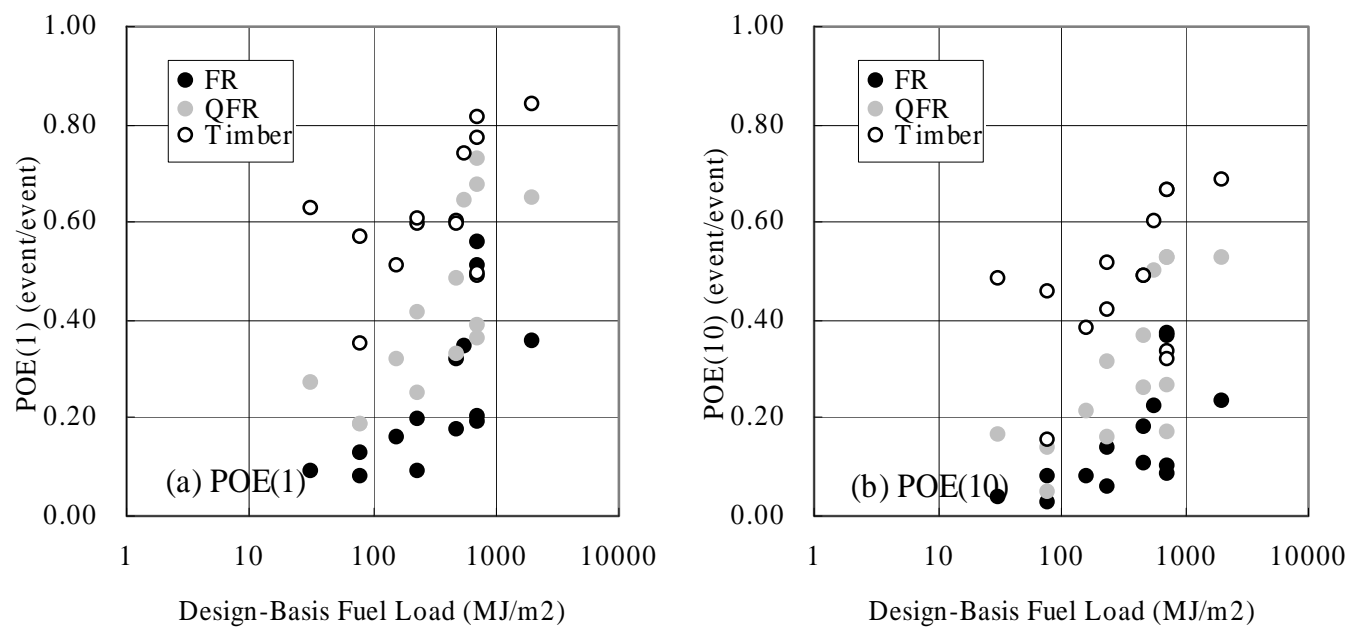

Fig. 9. POE vs. Design-Basis Fuel Load at Room of Fire Origin.

\section{TRANSITION FROM SMALL TO EXTREME DAMAGE}

Shifting the focus from small to less frequent but larger damages, this section discusses an alternative procedure to represent the risk curve all over the range of damages in a more mechanistic manner. The method relies on the following assumptions derived from some findings above:

- Floor area at risk has a lognormal distribution (Fig. 4).

- All the area vs. POE risk curves for different floor areas follow a single non-linear function ("Base Function") of area damaged by fire only up to the floor area of the building, though in reality these curves vary substantially size by size (Fig. 5).

- Base Function is given by $Y=P O E(1) *\left(a * \log (X)^{2}+b * \log (X)\right)$, where $X$ denotes area damaged by fire, and $a$ and $b$ are parameters to be estimated.

- $\quad$ POE for each building size equals zero above area exceeding the floor area (Fig.5).

Figure 10 gives an example for the procedure. Figure 10 (a) shows a building size distribution function: average logarithmic area is 1.5 and coefficient of variance of logarithmic area is 0.2 while the total number of data is assumed to be ten thousands here. If this distribution is given, its survival function, i.e. the ratio of buildings exceeding a specific level of floor area to the total number of buildings can be estimated as in Fig.10 (b) ("Reduction Factor"). Base Function in Fig. 10 (c) (POE(1)=0.6, $a=-0.005$ and $b=-0.2$ ) needs to be multiplied by Reduction Factor to take account of the plateau of size-by-size component risk curves as observed in Fig. 5. Thus, the result of the procedure will be Fig.10 (d), the summation of all component risk curves corresponding to different floor areas, some of which exemplified in Fig. 5.
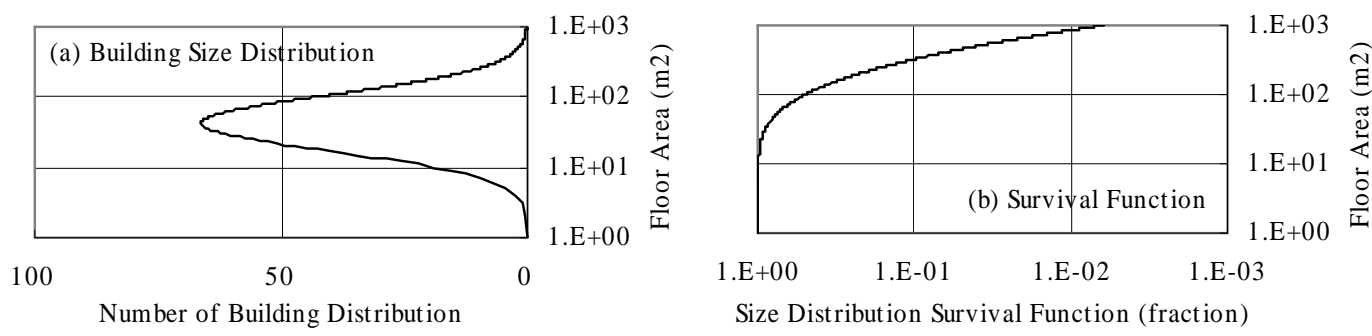

Fig. 10. Typical Model Example. 

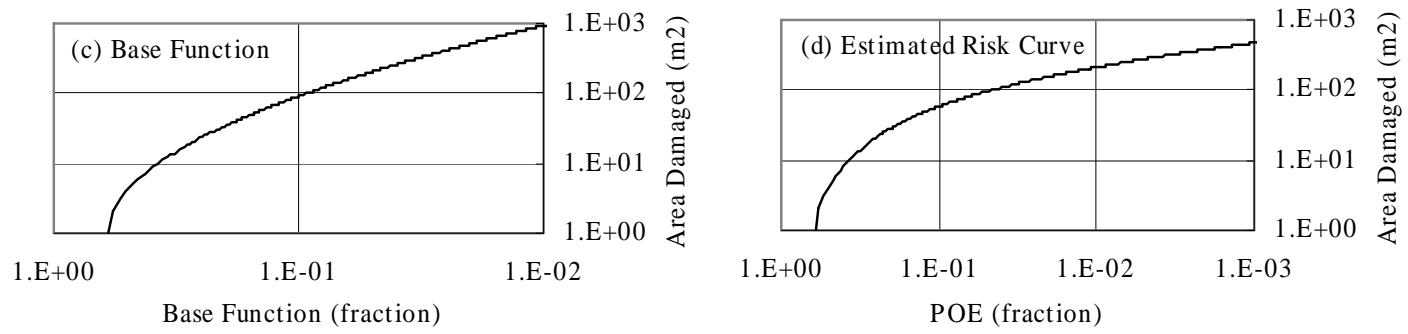

Fig. 10. Typical Model Example (contd).

The procedure is applied to statistical data: the test case here is, once again, timber houses since there are more than 60 thousand fire records available, including not only area damaged by fire but also the floor area of individual buildings. Figure 11 gives the results. The distribution function on building size (Fig.11 (a)) was directly obtained from the statistical samples: logarithmic mean of the floor area of 2.05 and standard deviation of 0.24. Only the two parameters for Base Function (Fig.11 (c)) were solved using a spreadsheet application to minimize estimation errors between the model and the risk curve: $a=-0.091$ and $\mathrm{b}=-0.02$.

Reduction Factor (Fig.11 (b)), or the survival function from the size distribution, remains roughly the unity up until a little less than 100 square meters. In this range, the risk curve estimated (Fig.11 (d)) is virtually the same as the Base Function. Comparing Figs. 11 (b) and 11 (d), it is evident that the sharp fall in Reduction Factor above 100 square meters determines the sudden "yielding” of the risk curve.

The model risk curve accords very well with observations all across the spectrum of damages with only one exception at the ultimate stage. The maximum area damaged of 3260 square meters was recorded in a building of the same floor area with the damage (indicating a complete damage) in Hyogo in the morning of January 17, 1995: the earthquake day. It is hoped that the accordance of the model will be improved by excluding post-earthquake events in the way in which the FR apartment fires in Hyogo were dealt with above.
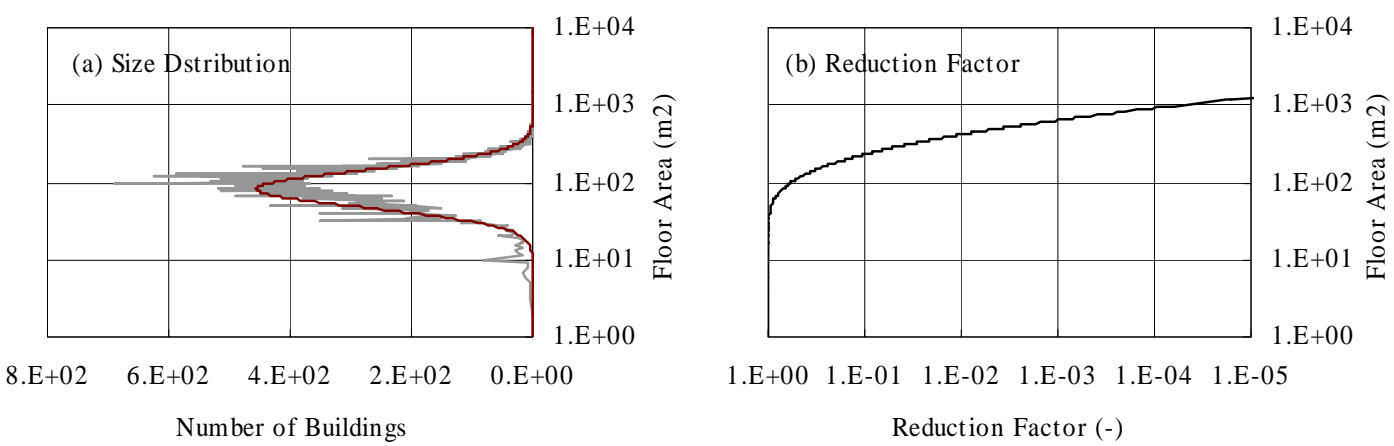

1.E+00 1.E-01 1.E-02 1.E-03 1.E-04 1.E-05

Reduction Factor (-)
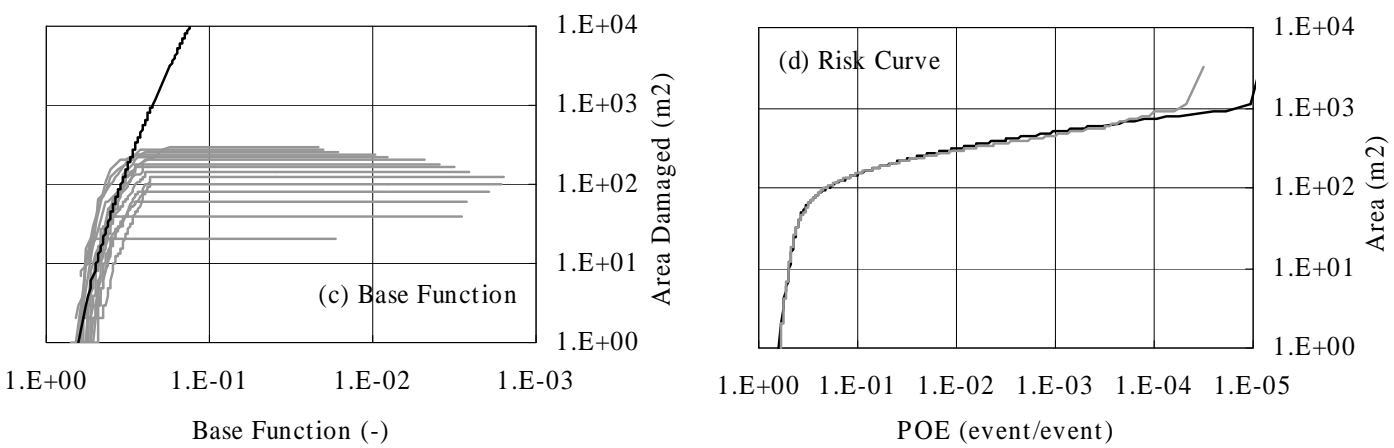

Fig. 11. Estimated Risk Curve Using a Base Function and Floor Area at Risk Distribution. 
The above analysis used the distribution of floor area directly derived from the data available in fire statistics. However, even the parameters determining the distribution (i.e. Size Distribution) or its survival function (Reduction Factor) as well as Base Function can be estimated using some solver function of spreadsheet software without knowing the parameters a priori. This means that the procedure has a potential for use in determining size-related parameters that are unfortunately not recorded in the current statistics: the size of room or compartment of fire origin, the floor area of an apartment unit within a FR building, etc. Further analysis needs to be performed applying the procedure to other building categories.

\section{CONCLUSIONS}

The findings can be summarized as below:

- First, the applicability of HD model was tested against fire statistics from a wide range of uses of building in three types of construction. If distinguishing post-earthquake fires from others, it was confirmed that the model performs well in describing the overall profiles of fire risk in terms of area damaged by fire from minimum to maximum of a type of buildings at large.

- However, it was also found that the HD type of nonlinearity does not fit at all with a series of fire data from detached timber houses of exactly the same size. In this case, a curvature and a plateau best describe an individual risk profile, the former being the trend up to the latter, the latter being the logical maximum limit of area damaged, i.e. the size of the whole building itself.

- Focusing on the probability of relatively small damages, some factors were tested for their ability to explain the variance of such damages by a variety of uses of room. It was confirmed that the success of early-stage fire extinguishment efforts has a strong negative correlation with occurrence of small damages. Fire loads at the room of fire origin, too, have a potential for playing some role in determining the probability of such events.

- The final section proposed an alternative procedure to describe fire risk profiles, based on the findings summarized under the second point above. The new model consists of two elements as HD model does: Base Function and Reduction Factor. The former element corresponds with the preflattening stage up to the risk maximum limit, while the latter is derived directly from the distribution of building size, available in the fire statistics.

- In the example case on timber detached houses, the Reduction Factor was estimated based on the size distribution of such fire-involved houses obtained from fire statistics. However, both Base Function and Reduction Factor can be determined if given enough data to draw a risk curve without knowing the size information. Thus, the new model not only appears more mechanism-oriented, but also has a potential to be useful in extracting structural size-related information such as the size of room, compartment, apartment unit, etc, which otherwise is not available in the fire statistics of Japan.

\section{REFERENCES}

[1] Ramachandran, G., (1982) Properties of Extreme Order Statistics and their Application to Fire Protection and Insurance Problems, Fire Safety Journal, 5: 59-76, doi:10.1016/0379$\underline{7112(82) 90007-8}$

[2] Hasofer, A. M. and Thomas, I. R., "Probability Distribution of Fire Losses,” Fire Safety Science -Proceedings of the Seventh International Symposium, International Association for Fire Safety, 2002, pp.1063-1072.

[3] Hanayasu, S., Kajiyama, M., and Sekine, K., (2002) Statistical Analysis of Industrial Accidents by Risk Curve, Research Reports of the National Institute of Industrial Safety, NIIS-RR-2001: 43-54.

[4] Tillander, K., "Utilization of Statistics to Assess Fire Risks in Buildings," VTT Publications, No.537, 2004.

[5] Kobayashi, Y. and Nozaki, H., "A Statistical Method to Evaluate Fire Risks in Non-Residential Buildings in Japan” Fire Safety Science -- Proceedings of the Eighth International Symposium, International Association for Fire Safety, 2005, pp.341-352. 
[6] Hardin, B. O. and Drnevich, V. P., (1972) Shear Modulus and Damping in Soils: Design Equations and Curves,” Journal of the Soil Mechanics and Foundations Division, ASCE, 98: GT7: 667-692.

[7] Handbook for Manual of Fire Reports, $8^{\text {th }}$ edition, $4^{\text {th }}$ printing, Tokyo Horei Publishing Co., Ltd., Tokyo, 2003

[8] Kobayashi, Y., "Non-Structural Building Components: Seismic Damage and Potential Failure of Fire Spread Prevention,” Fire Safety Issues on Seismically Damaged Buildings, Architectural Institute of Japan, Tokyo, 2007, p.7/14.

[9] Sekizawa, A., Ebihara, M., Notake, H., Kubota, K., Nokano, M., Ohmiya, Y. and Kaneko, H., (2000) Occupants' Behaviour in Response to the High-Rise Apartments Fire in Hiroshima City, Fire and Materials, 23: 297-303, doi:10.1002/(SICI)1099-1018(199911/12)23:6<297::AIDFAM702>3.0.CO;2-2

[10] Hagiwara, I., Evaluation Procedure of Performance-Based Design in Japan, Fire Safety Engineering - International Seminar, 2007. 